\title{
SIMULAÇÃO DO PROCESSO DE TREFILAÇÃO DE AÇOS BAIXO CARBONO*
}

Vanessa Moura de Souza ${ }^{1}$

Tomaz Fantin de Souza ${ }^{2}$

Eduardo Cristiano Milke

Alexandre da Silva Rocha

\section{Resumo}

Desde os anos 60, com o desenvolvimento do Método de Elementos Finitos (FEM) e a sua aplicação via métodos computacionais, a simulação numérica é uma ferramenta que está sendo cada vez mais utilizada para o conhecimento dos processos de fabricação, além de sugerir melhoria dos parâmetros na fabricação de peças. A utilização da simulação numérica permite evitar gastos desnecessários e perdas, investimentos em protótipos e testes dispendiosos, bem como para melhorar a qualidade do produto acabado.Neste trabalho são comparados os valores da força de trefilação necessária para fabricar arames de aço baixo carbono, para uma redução, medidos através do método de elementos finito e cálculo utilizando a equação de Siebel. Com este trabalho foi obtido a modelagem computacional do processo de trefilação, comparativo entre os métodos de medição da força de trefilação, maior compreensão do processo de trefilação e das propriedades mecânicas de arames trefilados.

Palavras-chave: Trefilação de arames; Simulações computacionais; Força de trefilação.

\section{Abstract}

LOW CARBON STEEL WIRE DRAWING PROCESS SIMULATION

Since the sixties, with the development of the Finite Element Method (FEM) and its application through computational methods, the numerical simulation is one of the most used tools to acquire a better knowledge of the manufacturing process, and it also suggests improvements to process parameters. The use of numerical simulation allows to avoid unnecessary expenses and losses, investments in costly prototypes and tests, as well as to improve the quality of the finished product. This paper compares the values of the required wire drawing strength to produce low carbon steel wire, for only one reduction step, measured by the finite element method and the Siebel equation. With this paper was obtained the computational modeling of the wire drawing process, comparison between the methods for measuring the wire drawing strength, better understanding of the wire drawing process and the mechanical properties of drawn wires.

Keywords: Wire drawing; Computational simulations; Wire drawing strength.

1 Engenheira Mecânica, Estudante de Mestrado, Processos de Fabricação, Universidade Federal do Rio Grande do Sul, Porto Alegre, Rio Grande do Sul, Brasil.

2 Engenheiro Mecânico, Mestre, Professor, Conformação Mecânica, Insituto Federal Sul Riograndense, Sapucaia do Sul, Rio Grande do Sul, Brasil.

3 Engenheiro Mecânico, Doutor, Coordenador do Curso de Engenharia Mecânica, Conformação Mecânica, Insituto Federal Sul Riograndense, Sapucaia do Sul, Rio Grande do Sul, Brasil.

4 Engenheiro Mecânico, Doutor, Professor, Processos de Fabricação, Universidade Federal do Rio Grande do Sul, Porto Alegre, Rio Grande do Sul, Brasil. 


\section{INTRODUÇÃO}

A utilização de simulações computacionais, método de elementos finitos, como uma ferramenta para a avaliação da força permite um conhecimento mais completo e aprofundado das propriedades mecânicas, campo de tensões, deformações e forças envolvidas na realização deste processo. Além disso, o desenvolvimento de um modelo numérico computacional pode permitir uma metodologia de estudo do processo de trefilação de arames que será utilizada em estudos posteriores [1]. Também é sabido que a força de trefilação é o parâmetro mais importante a ser controlado neste processo, pois erros relacionados a sua avaliação podem acarretar quebras nos arames ou perdas energéticas excessivas. Existem diversos métodos utilizados para realizar a medição da força de trefilação: equações encontradas na literatura, método de elementos finitos, simulações computacionais e medições experimentais $[2,3]$.

O controle dos parâmetros de processo como o atrito e a força podem contribuir em uma melhor qualidade do produto e na realização de processo menos poluente, que reduza o consumo energético e perdas desnecessárias de material [4]. Será apresentado neste trabalho, o desenvolvimento de um modelo computacional que reproduza o processo de trefilação em estudo, este modelo poderá ser utilizado futuramente para uma análise mais detalhada do processo de trefilação. Desta maneira, é possível utilizar os dados para identificar e entender as propriedades mecânicas, campo de tensões, deformações e forças envolvidas na realização deste processo.

\section{MATERIAIS E MÉTODOS}

\subsection{Simulações Numéricas Computacionais}

Foi desenvolvido um modelo numérico computacional para reproduzir o experimento. As simulações foram realizadas no software Simufact.forming® do Grupo de Engenharia de Superfícies do Laboratório de Transformação Mecânica (GES-LdTM) da Universidade Federal do Rio Grande do Sul. Na Tabela 1 são apresentados os parâmetros das simulações numéricas computacionais realizadas para descrever o experimento.

Tabela 1. Parâmetros das simulações numéricas computacionais

\begin{tabular}{|l|l|}
\hline Análises & Mecânicas Axissimétricas [Elementos Finitos] \\
\hline Número de elementos & 500 [tipo: QUAD] e 5 radiais \\
\hline Material & Baixo Carbono (banco de dados simufact.forming) \\
\hline Velocidade de trefilação & $2 \mathrm{~mm} / \mathrm{s}$ \\
\hline Diâmetro inicial e final & 5,5 e $4,5 \mathrm{~mm}$ \\
\hline Temperatura inicial & $20^{\circ} \mathrm{C}$ \\
\hline \multicolumn{1}{|c|}{$\varphi_{a}$} & $41 \%$ em redução de área de seção transversal \\
\hline Ângulos de fieira (2a) & $8^{\circ}$ \\
\hline Módulo de Young & $210 \mathrm{GPa}$ \\
\hline
\end{tabular}

O modelo axissimétrico utilizado para a trefilação é apresentado na figura 1: 


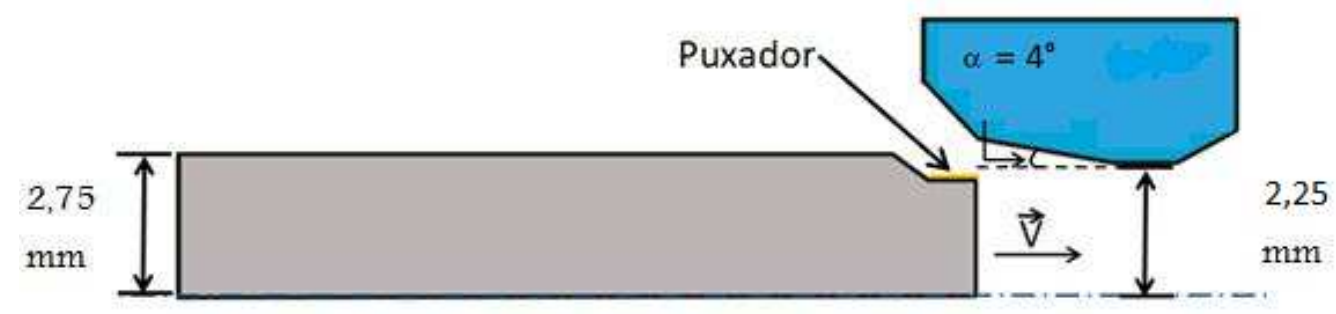

Figura 1. Modelo para trefilação

Através dos resultados simulados foi possível obter o perfil dos valores para o processo de: tensões residuais, deformações e força de trefilação.

\subsubsection{Descrição da simulação computacional}

Gerou-se um modelo numérico a partir do software Simufact.formingGP ${ }^{\circledR}$ para o estudo do estado de tensões residuais gerado pelo processo de trefilação do aço baixo carbono. Primeiramente, desenvolveu-se um modelo axissimétrico bidimensional que permite que se simule uma fatia da barra, porém os resultados são extrapolados para o restante da geometria, o que permite reduzir o tempo de cálculo computacional. Neste modelo, por considerações geométricas de simetria e a fim de diminuir o tempo de cálculo foi simulada metade do arame.

$\mathrm{O}$ arame modelado possui $100 \mathrm{~mm}$ de comprimento e 2,75 $\mathrm{mm}$ de diâmetro e a fieira tem comprimento total de $42,5 \mathrm{~mm}$.

Os valores das tensões residuais para as direções tangencial e axial após trefilação devem ser próximos na superfície, o que condiz com o resultado simulado [5].

\section{RESULTADOS E DISCUSSÃO}

Nas Figuras 2 e 3 são apresentados o início da simulação e o modelo de elementos finitos desenvolvido para obtenção dos resultados de força, deformações e tensões residuais.

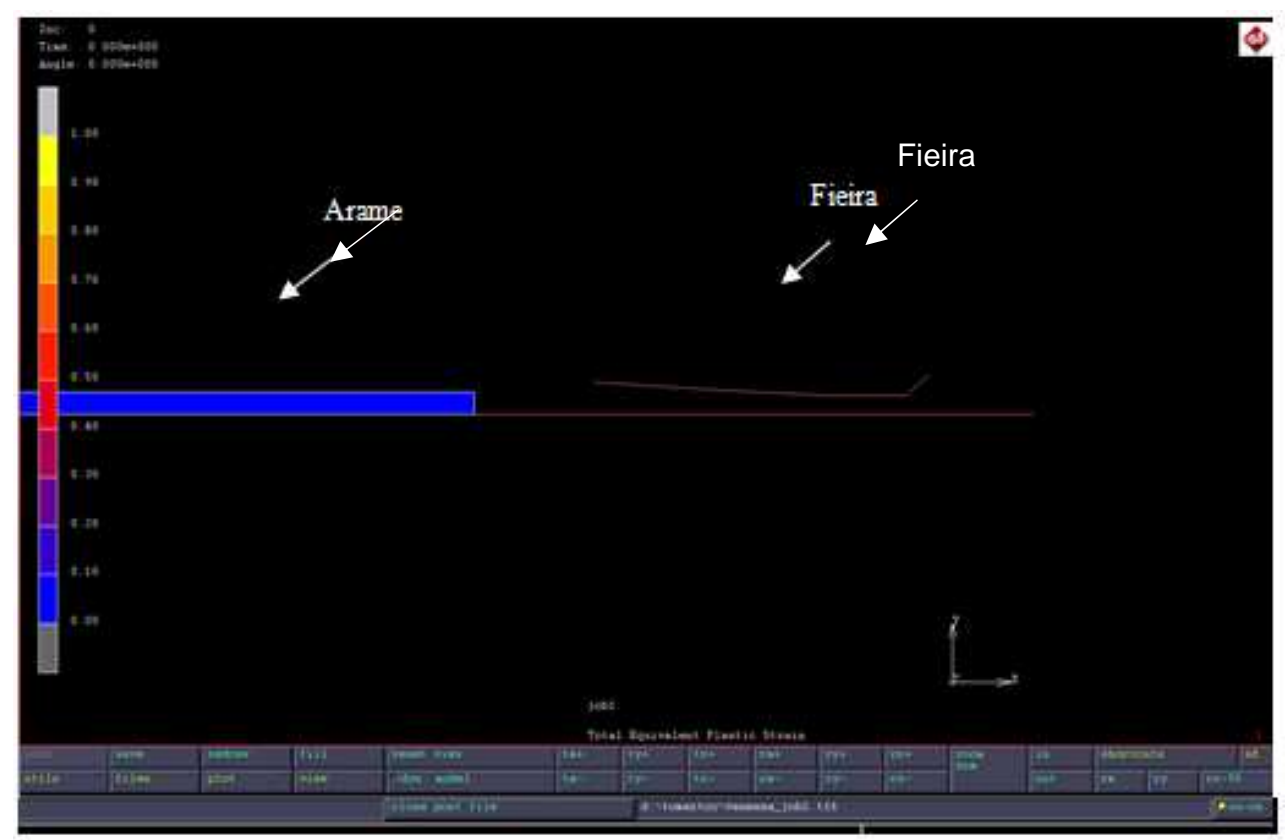

Figura 1. Início do processo de trefilação simulada. 


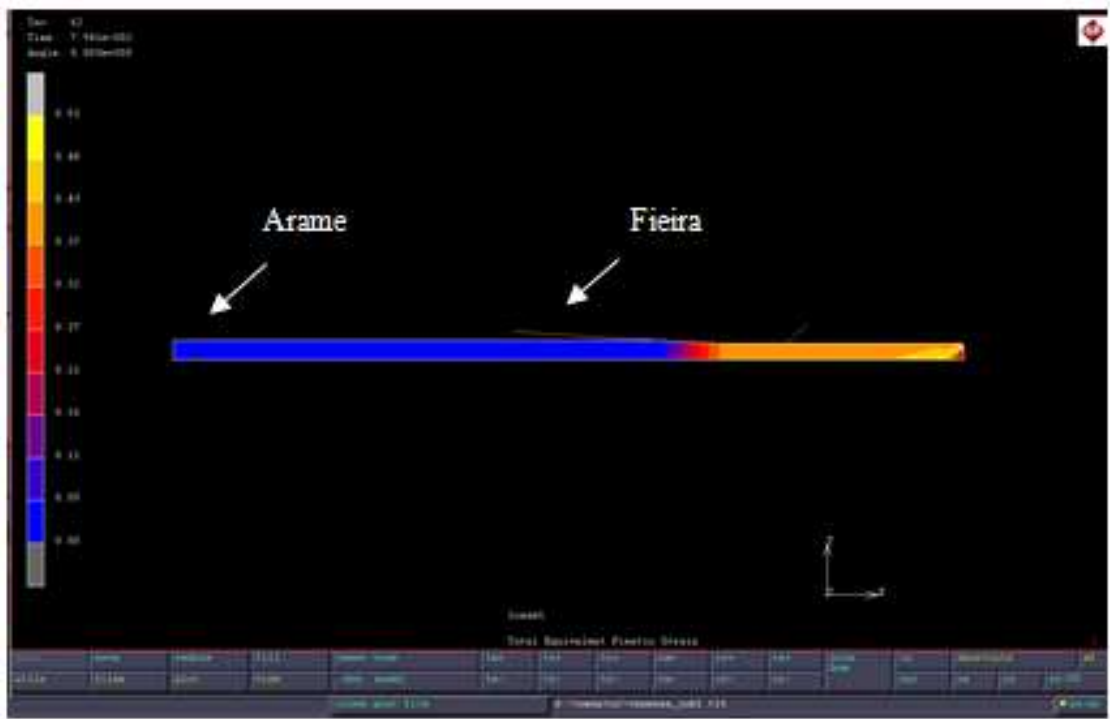

Figura 2. Momento em que o arame está sofrendo redução de área na simulação do processo de trefilação

\subsection{Força de Trefilação}

$\mathrm{Na}$ Tabela 2 são apresentados os resultados para a força de trefilação medida experimentalmente e simulada através de elementos finitos.

Tabela 2. Resultados para a força de trefilação obtidas por elementos finitos

\begin{tabular}{|l|l|l|}
\hline Simulação & Corrida I & Corrida II \\
\hline $8376 \mathrm{~N}$ & $5391 \mathrm{~N}$ & $6275 \mathrm{~N}$ \\
\hline
\end{tabular}

Através das simulações computacionais obteve-se um valor de $8376 \mathrm{~N}$ para a força de trefilação. Este valor implica em uma diferença de $35 \%$ em relação à corrida I e $25 \%$ em relação à corrida II do material em estudo.

Estas diferenças são consideradas altas, embora dentro do valor teórico aceitável para uma comparação entre experimento e simulações computacionais que é de $30 \%$, segundo critérios adotados pelo Instituto IUL de Dortmund Alemanha que é referência mundial em simulação. Este desvio deve-se a diversos fatores, dentre eles: consideração da curva real de escoamento do material, lubrificação experimental ineficiente, diferenças geométricas e erros de limitação do software.

\subsection{Deformação Plástica}

A Figura 4 demonstra um resultado global de deformação plástica de $41 \%$, valor que pode ser comprovado pela equação para a deformação real do processo. Este resultado é um indicativo de que o modelo numérico computacional foi eficiente para o cálculo das deformações. 


\section{$6^{\circ}$ Trefilação}

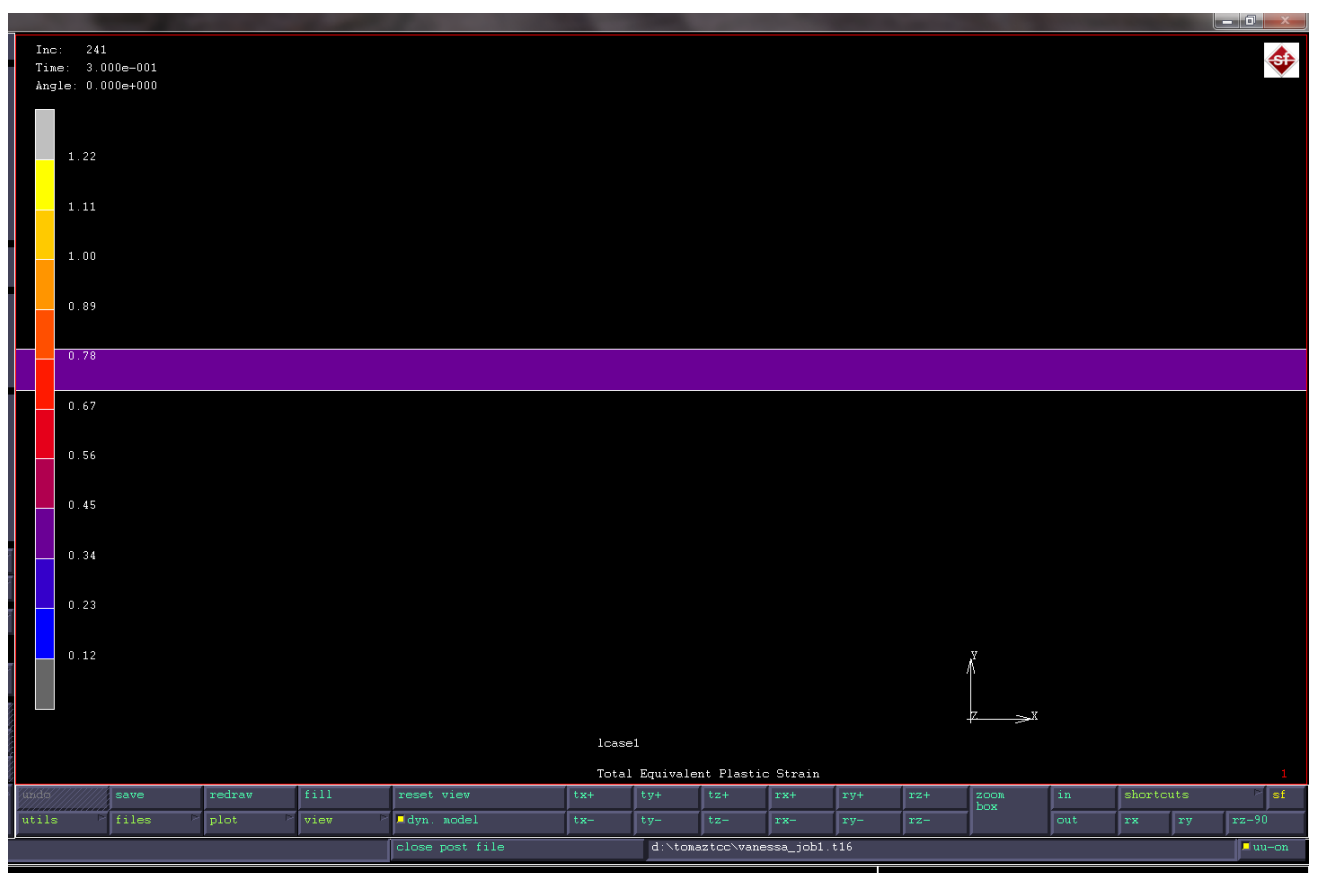

Figura 3. Resultado da deformação plástica global

Na Figura 5 são apresentados os resultados para a deformação plástica localizada para cada um dos elementos da barra após a trefilação.

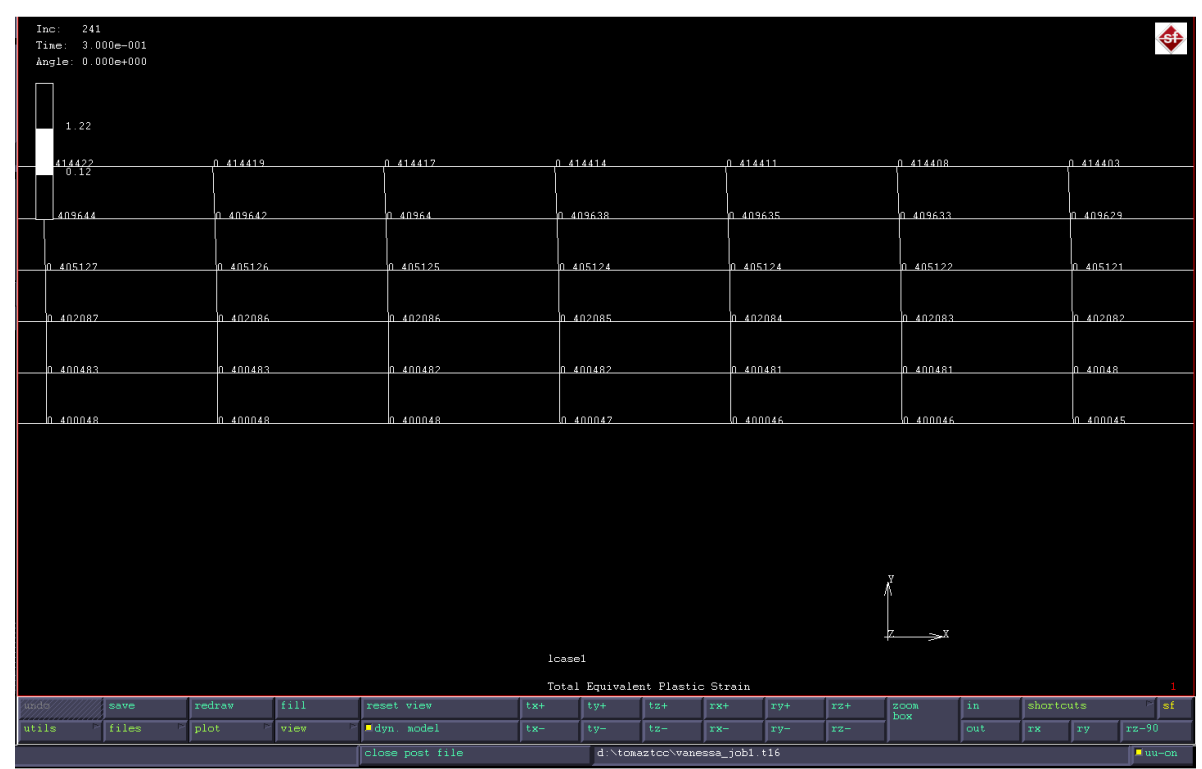

Figura 4. Resultados para a deformação plástica localizada

Na Figura 6 são apresentados os resultados para a deformação plástica em cada um dos elementos do modelo desenvolvido. Como o modelo possuía cinco elementos radiais, foi calculada a média dos valores de deformação plástica para cinco elementos centrais, para que fossem evitados os efeitos do início e final da trefilação. Como foi desenvolvido um modelo axissimétrico, a média dos valores de deformação plástica para a metade da barra foi extrapolada para a barra toda, onde 0 representa o centro e $-2,25 \mathrm{~mm}$ e 2,25 $\mathrm{mm}$ as extremidades. 


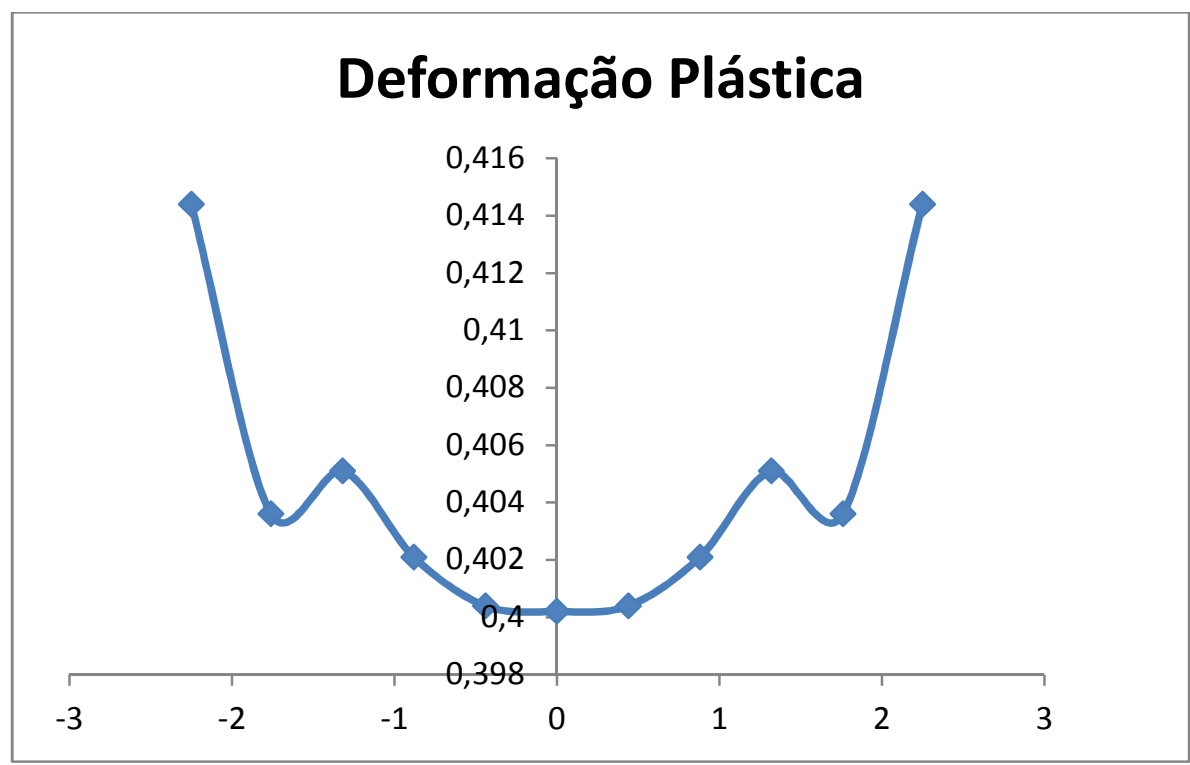

Figura 5. Resultados para a deformação plástica

Através da Figura 6 é possível perceber que os elementos do material, após a trefilação, sofrem deformação heterogênea. Para o centro da barra, o valor da deformação plástica atinge valores próximos a $0,4(40 \%)$, já para as regiões superficiais, a deformação plástica alcança valores em torno de $0,414(41,4 \%)$.

Estes resultados demonstram que os elementos próximos à fieira sofreram maior deformação plástica que os elementos centrais. Esta deformação heterogênea do material sugere que o material irá apresentar um campo de tensões residuais após a realização do processo. Esta deformação heterogênea ocorre, pois o material está sofrendo tensões de tração e compressão de formas diferenciadas, sendo que algumas regiões como a central estão sofrendo tensões trativas, já as regiões superficiais estão sofrendo tensões cisalhantes.

\subsection{Tensões Residuais}

As Figuras 7, 8, 9 e 10 apresentam o comparativo dos resultados de tensões residuais para as direções axial e radial simulados para o modelo de elementos finitos axissimétrico mecânico com fieira rígida e seus modelos computacionais desenvolvidos.

Como esperado [5] na direção axial, para o centro da barra, as tensões apresentam comportamento compressivo; já para a superfície, apresentam comportamento trativo. Na direção radial, as tensões são compressivas em toda a barra aproximando-se de zero na superfície. Esse comportamento dos perfis de tensões residuais é obtido porque a redução de área é maior que $1 \%$, caso contrário o sentido das tensões seria invertido. 


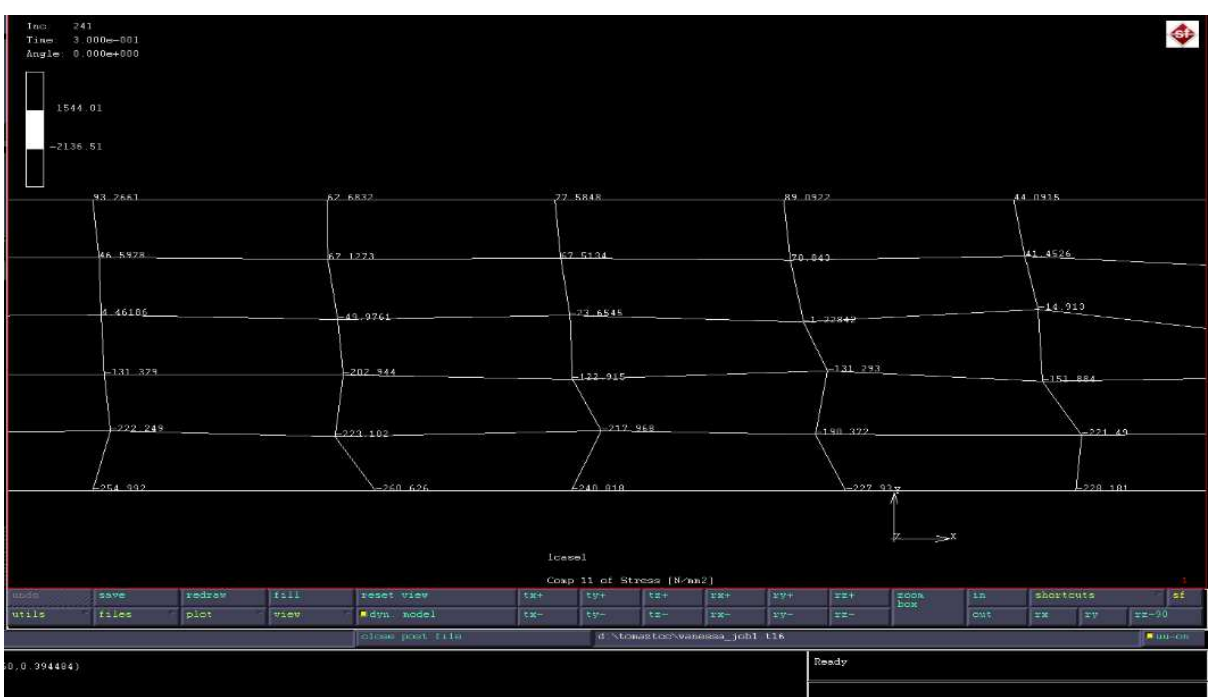

Figura 6. Tensões residuais axiais

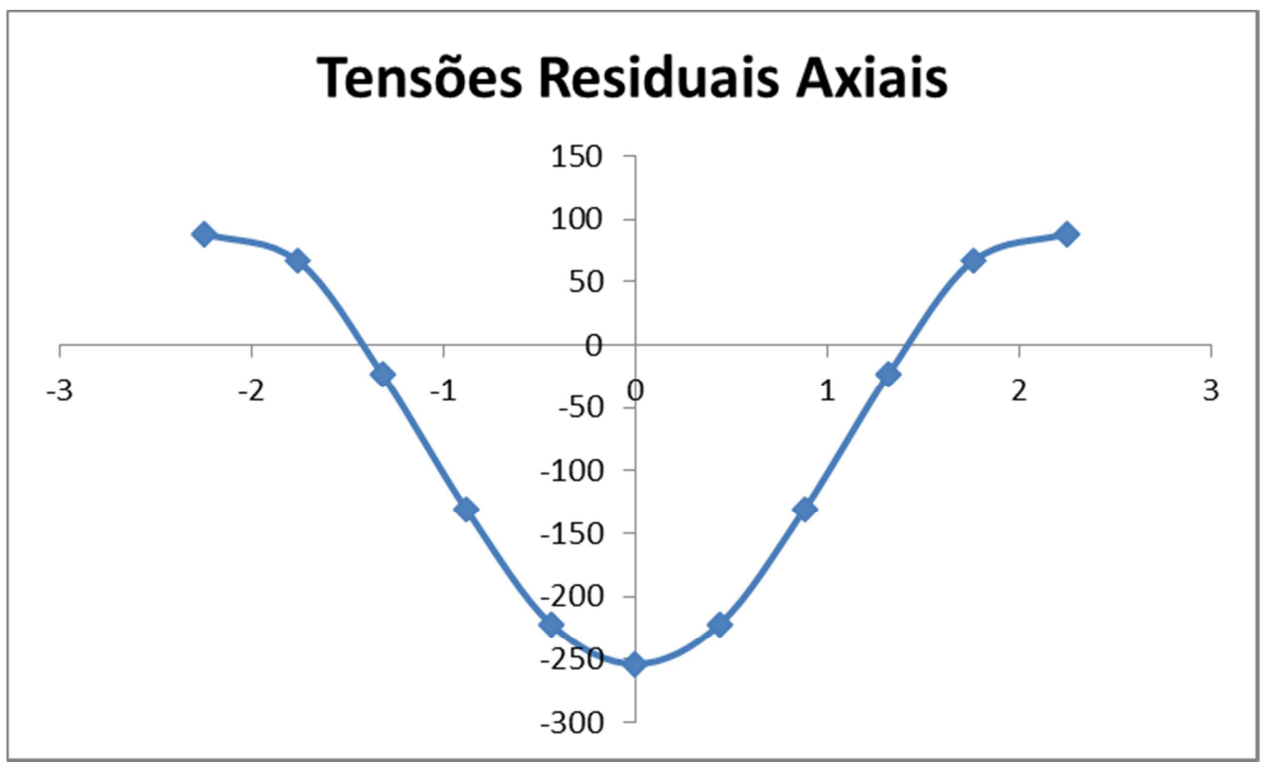

Figura 7. Gráfico tensões residuais axiais

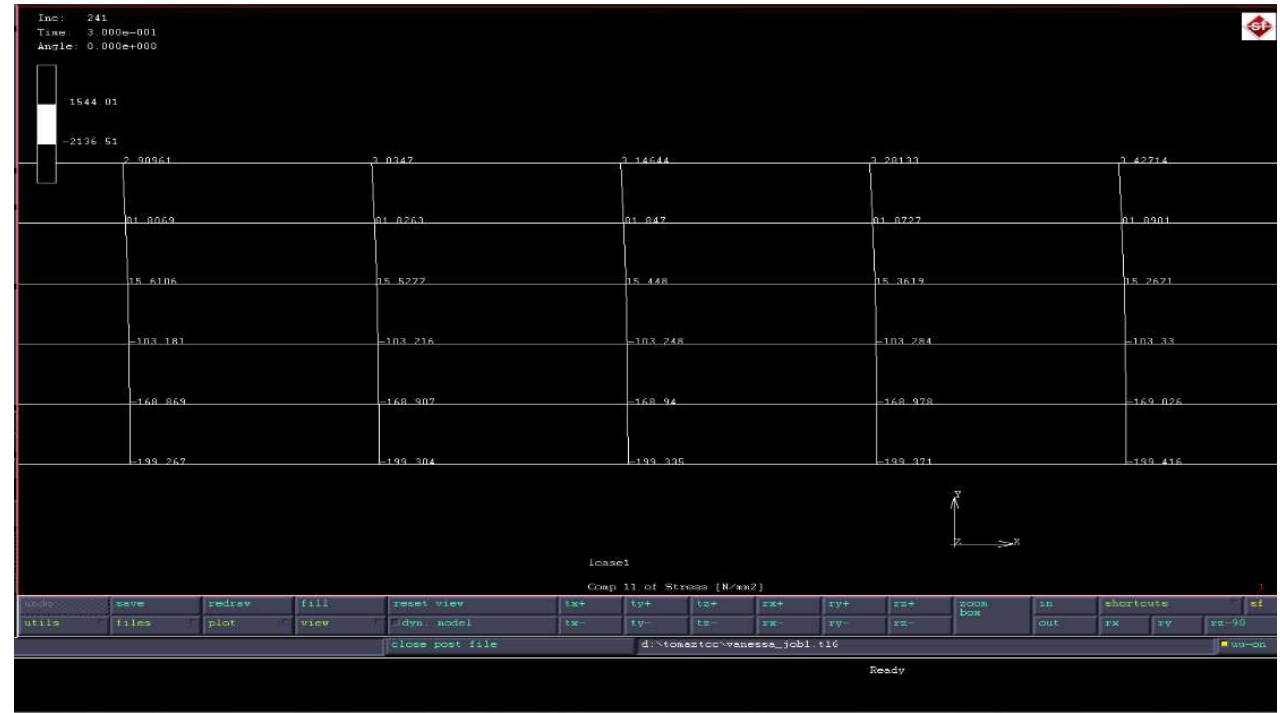

Figura 8. Tensões residuais radiais 


\section{Tensões Residuais Radiais}

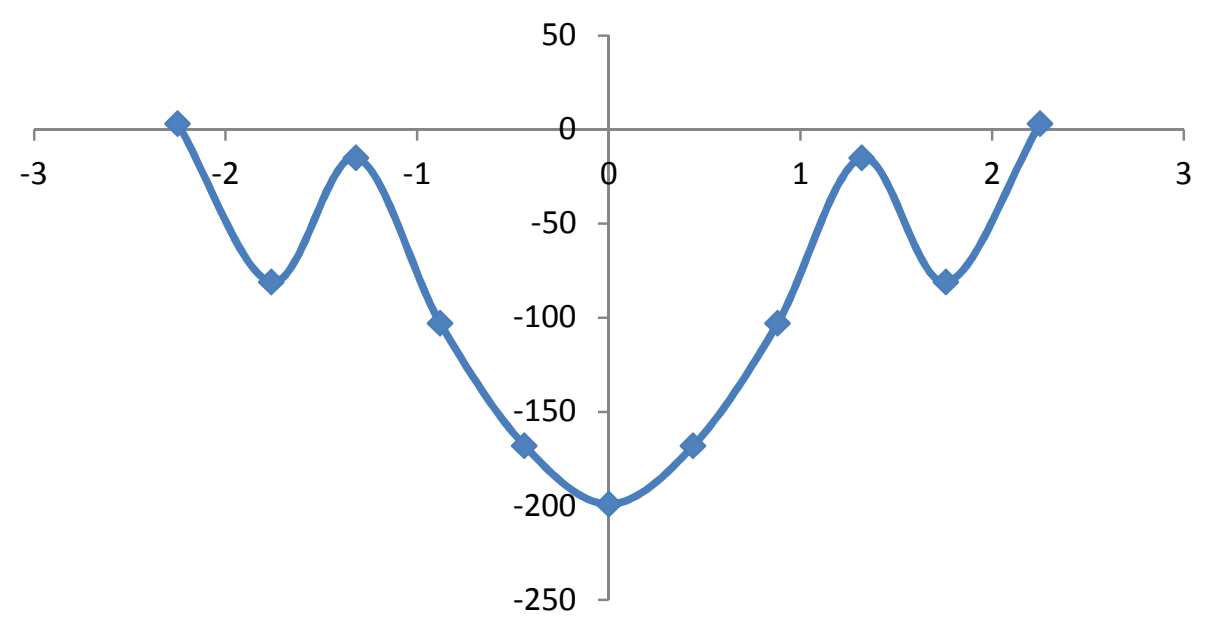

Figura 9. Gráfico tensões residuais radiais

Para a direção axial: Nas Figuras 7 e 8 observa-se tensões trativas na superfície da barra com valores que giram em torno de $89 \mathrm{MPa}$. No centro da barra, os valores das tensões calculadas aproximam-se de -250 MPa compressivos.

Para a direção radial: Nas Figuras 9 e 10 a simulação apresenta resultado próximo a zero na superfície da barra e comportamento compressivo para o centro. Na região central o modelo apresentou um valor compressivo de -199 Mpa.

Analisando os perfis de tensões residuais pode se afirmar que as tensões envolvidas são de uma alta magnitude quando comparadas com a tensão de escoamento inicial do processo. Além disso, nota-se que os valores de tensões residuais para as direções axial e radial apresentam resultados próximos para o centro da barra (devido às direções serem iguais nesse ponto), o que é consistente com a literatura pesquisada e as condições iniciais de modelamento [5].

\section{CONCLUSÃO}

Ao longo deste trabalho foram discutidos diversos aspectos relativos ao processo da trefilação de arames de aço baixo carbono objetivando-se encontrar valores de força, deformações e tensões residuais.

A partir dos resultados obtidos pela simulação computacional conclui-se que:

- Foi possível validar o modelo computacional simulado através da trefilação experimental do material em questão e da comparação da equação da força de Siebel.

- Foi possível reproduzir-se via elementos finitos o processo experimental da etapa de trefilação através de uma modelagem mecânica axissimétrica com fieira rígida. A validação da simulação foi realizada através da comparação da deformação global equivalente e dos perfis de tensões residuais obtidos.

- A força de trefilação simulada foi de 8376 N o que dá uma diferença de $35 \%$ para a corrida I e de $25 \%$ para a corrida II do material em estudo, estas diferenças são originadas pela equação utilizada pelo software de simulação computacional, que é diferente da equação tensão deformação do material, já que as forças de trefilação experimentais indicam uma diferença entre os dois aços. O software é programado com base nas curvas de escoamento para aços baixo carbono. 
- O perfil de deformações sugere diferenças entre a deformação plástica no centro e na superfície do material, o que indica deformações plásticas heterogêneas o que levará ao surgimento de tensões residuais.

- O perfil de tensões residuais demonstra para a direção axial um comportamento trativo na superfície e compressivo no centro da barra. Para a direção radial, o valor da tensão residual é próximo a zero na superfície e alcança um máximo negativo no centro da barra. Estes comportamentos estão condizentes com a literatura pesquisada e são um indicativo de que o modelo reproduz corretamente o experimento realizado em laboratório.

- O modelo computacional de trefilação validado neste trabalho poderá futuramente ser aplicado em indústrias de trefilação para utilizar parâmetros ótimos no processo que agreguem maior eficiência energética, produtividade e redução de perda metálica, tornando assim o processo de trefilação mais sustentável tanto ambientalmente quanto economicamente.

\section{REFERÊNCIAS}

1 Tekkaya AE. State-of-the-art of Simulation of Sheet Metal Forming. Journal of Materials Processing Technology. 2000; 103:14-22.

2 Godfrey H, Richards F, Saron S. The benefits of using wiredrawing dies with smaller included angles and longer nibs. Wire Journal International. 2000; 33(6):102-113.

3 Martins P, Rodrigues J. Tecnologia Mecânica Volume 1. Lisboa: Escolar, 2005.

4 Dieter GE. Metalurgia Mecânica. 4ㄹ Edição. Rio de Janeiro: Guanabara Dois, 1996.

5 Atienza JM, Elices M. Influence of Residual Stresses in the Stress Relaxation of Cold Drawn Wires. Materials and Structures. 2004; 37(269):301-304. 